M. Correa Pastene

\title{
Las fiestas nupciales en Venecia
}

ENECIA es para los enamorados, la sede ideal de los ensueños y del dulce abandono en el aislamiento y el misterio de sus canales, y de una fastuosa decoración del cielo y de la tierra. Sentirse en medio de las aguas quietas, desligados de la tierra y sus afanes, de los hombres y las cosas, en el absorbente egoismo de dos almas fundidas en una, y mirar el cielo que enrojece en el crepúsculo y las estrellas que se reflejan en las aguas, y saberse lejos y cerca de todo humano socorro y hallar en los ojos tiernos que nos miran la dulzura de la estrella, el espejeo de las aguas y el calor de un corazón devoto, es una legitima ambición y un amable sueño.

La góndola de levantada proa como una regia babucha persa. cobija en su valdaquino de colores las parejas que acuden de todas partes a recibir el bautismo de una felicidad ideal: y en tanto ella trenza la plática confidencial. la góndola traza sobre el espejo de las aguas estela de encajes y el gondolero. de pie en la proa. hincha el aire callado con las notas de un canto sentimental. El sol se hunde enrojeciendo las aguas y el véspero sacude el gallardete.

Perdida su corona ducal, muerto su imperio sobre el Adriáfico y fenecido aquel intenso comercio que hizo de Venecia el

(1) Véase en Afenea N.o 10 un arfículo de D. Augusto Iglesias, Los rifuales con el mars. 
emporio de los productos del Asia. Africa y Europa que sus barcos. llevaban a todas partes: acabado su poderio que pesó en los destinos de los limites de tres continentes y apagado el eco de sus triunfos militares. quedan el prestigio de sus artes, sus palacios de mármol y jaspe, sus pinturas y esculturas. y la originalidad de una ciudad levantada sobre el agua: y a ella acuden a estudiarla. como que es un enorme museo, y a gozarla en el misterioso atractivo de un mar encadenado enamorados y estudiosos.

Venecia parece creada para sede de amor.

Desde que nació. levantada por las manos hábiles de los romanos empujados hacia la costa por los bárbaros que cayeron del norte y desde que Atila en el siglo IV llegó hasta las orillas del Adriático y tomó Aquilea, Venecia fué sitio de grandes y públicas fiestas nupciales.

Apenas construidas las primeras casas y levantado el templo de Forcello, sus habitantes, ciudadanos romanos de aristocrática raigambre, convinieron. sin duda como signo de seguridad y fraternidad, destinar un día del año para bendecir todos los matrimonios concertados durante su curso.

Ningún historiador podrá fijar la fecha en que principió esta fiesta llamada de .Los Novios, o edella Marie. porque... ninguna costutmbre nace de un edicto o de acto público de que se tome noía en los archivos: principian poco a poco, y si cuadra a la ndole y carácter de los comuneros. se hace general. Pero es lo cierto que la fiesta se celebraba desde tiempo inmemorial.

Cuando se construyó, y fué la segunda iglesia levantada por los refugiados, San Pedro del Castillo en la isla de Santa Elena, una de las últimas en el grupo de ochenta que más o menos forman hoy la ciudad, a ese templo acudian las parejas.

El 2 de Febrero de cada año se reunian en San Pedro. Llegaban primero los novios con una cajita, que seria de madera tallada, en la cual tenian la dote de la novia; luego llegaban éstas y sus padres y comitiva. 
El obispo decía la misa, predicaba las virtudes caseras. la fidelidad y el amor que uniria los novios, y luego los bendecía.

Terminada la ceremonia, desfilaban las góndolas con los concurrentes, recorrian los canales y tornaban a casa; y un festejo general animaba todos los hogares, porque el que no celebraba la reciente boda de sus hijas, celebraba el aniversario de las anteriores. Asi la nobleza, unida y concorde, estrechaba sus lazos y fomentaba aquella unión estrecha que le permitió gobernar durante trece o catorce siglos la república y dotarla de sabias leyes, de poderio y riqueza, de arte y felicidad.

Pero un dia aquella fiesta fraternal fué trocada en duelo. El año 943, estando listos los novios, preparado el obispo. espectantes y confiados parientes. amigos y pueblo dentro de la iglesia. cayó de golpe una banda de piratas eslavos y raptó las novias envueltas en sus velos nupciales y echándalos en sus barcos, bogaron hacia el continente.

Los nobles acudieron a sus góndolas-caballos de carrera y de batalla- dieron la alarma, acaudillaron gentes, vinieron los bauleras y ballistas de Santa María la Formosa y pusieron en fuga a los piratas y recobraron las novias.

Menos fecundas aquellas arenas que la tierra de Roma en el rapto de las sabinas, recibieron el nombre de campo sdelle Donzelles.

El terror invadió a padres y novios y la fiesta común fué abolida. Por miedo a los piratas, los matrimonios en adelante fueron individuales y se celebraron en San Marcos o en los palacios, que ya ornaban mármoles romanos.

Pero el pueblo, que gozaba del espectáculo y el común regocijo. no consentía de buen grado en la supresión de una fiesta tan sonada.

Cuenta Sansovino, citado por Ruskin (.Las Piedras de Venecias, tomo II, pág. 164 y 165 , edición Sempere, traducción 
de Carmen de Burgos: datos que doy para que D. Augusto Iglesias pueda comprobarlos). cuenta Sansovino. digo, que el Dux llamó a los bauleras de Santa Maria la Formosa para agradecerles la ayuda prestada en el rescate de los novios, y les preguntó qué querian.

$\mathrm{Y}$ ellos pidieron que en recuerdo de la sfiesta de los novios, y de la liberación de las novias, cada año en el aniversario (2 de Febrero), visitaran el Dux. la Dagaresa y la Senoria (Consejo) el templo de su isla.

- ¿Y si llueve? preguntó el Dux.

- Nosotros os regalaremos sombreros para protegeros, y si tenéis sed, os daremos de beber.

Y así fué convenido. Cada año iban el Dux, la Dagaresa y la Señoría en la barca oficial: el vicario les prestaba dos frascos de malvasía y dos naranjas y dos sombreros dorados. ornados con las armas dal Papa, el Dux y el Vicario.

El templo habia sido levantado por el obispo de Uderzo en 639. siguiendo el mandato de una visión que había tenido: y lo llamó de Santa Maria la Hermosa, en recuerdo de la belleza de la aparecida. Quemado dos veces, Tué reconslruido en 864 y en 1105. hasta que un tercer incendio en 1689 lo destruyó definitivamente. Hoy. según Ruskin, no queda en Santa Maria la Formosa ni una piedra de las que vieron las fastuosas comitivas de la fiesta ede los casados.

Porque así se llamó este remedo y simulacro de la primitiva efiesta de los novios».

Se escogian para ella doce muchachas de las más lindas. dos por cada uno de los seis distritos o sestiere en que se dividia la ciudad. Los nobles proveian largamente a doncellas festejantes de ricos ropajes, y el guardarropa y tesoro de San Marcos se encargaba de prestar ropas, joyas y adornos a las que carecian de ellos.

Tres dias duraba esta fiesta y era tanto su lujo y esplendor que acudian de todas partes a verla y participar. El 31 de Enero. las novias o las que llamariamos hoy reinas de la fiesta, y 
su corte, eran recibidas en San Marcos por el Dux y la Se. ñoria; y del Palacio pasaban a la iglesia, donde oian misa.

El 1. ${ }^{\circ}$ de Febrero era destinado a festejos públicos. Toda la población y los extranjeros tomaban parte: la laguna resonaba con música y cantos y los colores de banderas y empavezados de cientos de embarciones móviles teñian su cielo.

El 2 de Febrero iban el Dux. la Dagaresa y la Señoría de Venecia a la iglesia de Santa María la Formosa; oían misa y se organizaba un desfile de góndolas por los canales, pues cada cual quería pasar frente a su casa.

El tesoro ducal proveía largamente a estos festejos y la nobleza tomaba a su cargo vestir y aderezar a los concurrentes. Nunca los tesoros de San Marcos y las joyas y ropas de los nobles lucieron mejor.

El Dux Pedro Orseolo II al morir dejó en testamento las rentas de su fortuna para lucimiento de la fiesta -los casados. .

Pero la fiesta de clos casadoss. como antes la ede los novios, concluyó con una calamidad pública. Estalló en 1379 la terrible y desastrosa guerra de Chiazza: el Estado le destinó sus tesoros, los nobles y el pueblo sus hombres fuertes y sus embarcaciones; y el comercio se estancó, vino la carestia. le siguió la miseria y al salir de la guerra. el gobierno ducal endeudado, suprimió lodo recurso a la fiesta y acabó.

Pero otra fiesta nupcial había cobrado ya importancia: la del Dux con el Adriático.

Venecia dominó en el Adriático casi desde su fundación. pueblo insular, habitante de una ciudad cuyas calles son de agua y cuya locomoción hace por canoas, estaba destinado a dominar en el mar. Extendió su imperio por ambos lados del Adriático y las ciudades que no fueron colonias, fueron vasallas. Para certificar este dominio, la República impuso contribuciones a los navios mercantes que entraban en el gollo. de las cuales derivaron guerras; pero se mantuvo firme e hizo prevalecer su dominio contra poderosos reyes. Prohibió sobre todo la entrada de navios de guerra, hasta el punto de que ni por cortesía lo toleró. 
En 1630 el Embajador de España previno al Dux que la Infanta María debia ir de Nápoles a Trieste para casarse con el rey de Hungria, hijo del Emperador: e iria en un navio de la armada real española. El replicó que la princesa sería tratada con todos los honores, pero que entraría en el Adriático en una galera de la República. Replicó el Rey que la peste habia infestado las naves venecianas y no era posible exponer la persona de María a un contagio: pero el Dux se mantuvo firme, porque las leyes de la República impedian el paso de un navio de guerra. El rey de España tuvo que someterse; un navio de la República condujo a la infanta entre fiestas y aquel regio aparato que el ducado desplegaba en sus relaciones con soberanos.

Por mantener su dominio trató con los turcos; hizo salir del gollo algunos navios de Fernando de Nápoles: impidió al Papa Pio II enviar galeras a Ancona, ni permitió que el Rey de Francia llevase las suyas al gollo.

$\mathrm{Y}$ las potencias reconocieron este hecho tradicional. firmemente establecido, y cuando querian cruzar el Adriático o se sentian amenazados de ataque de los lurcos a provincias italianas, reclamaban de Venecia, como dueño del mar, garantias de seguridad.

¿Por qué, se preguntaba el Papa Pablo V. los venecianos se proclaman soberanos del gollo? Todos los años hago leer una bula de excomunión contra los piratas y al hablar de este mar lo llamo snuestro mar Adriático. Pero... las bulas podían poco contra berberiscos y turcos; y si podian las galeras venecianas, fuertes y sólidas en la guerra. iViejos titulos que han servido a los italianos en 1922 para reclamar Trieste de Austria y todo el Véneto. en virtud de que el Adriático lué. para ellos, mare - nostrum!

Para hacer visible este dominio se recurrió a la ceremonia matrimonial. ¿Quién la inventó? No se sabe. D. Rafael Errázuriz U. en sa ciudad de los Dux, hace remontar la ceremonia al año 1000 y lantos, cuando era Dux Orseolo II. el mismo que al morir legó sus rentas a la fiesta de los casados, pero no aduce ningún documento. La crónica más antigua que 
reproduce refiere la ceremonia efectuada en 1177 cuando el papa Alejandro III entregó al Dux Sebastián Ziani el anillo de oro que simbolizaba el desposorio.

Si ya la fiesta se celebraba, el Papa la confirmó y solemnizó. Estaba agradecido a la República que ese año habia delendido su elección canónica contra el anti-papa Víctor IV. candidato del Emperador de Oriente, Barbarroja. Oton, hijo de Federico, cruzó al Adriático con una flota de 60 galeras contra Venecia, y la República. con 30 al mando del Dux Ziani, lo derrotó y tomó prisionero. Barbarroja se sometió, y Alejandro III escogió la ciudad de Venecia para celebrar la reconciliación. Vino el Emperador con gran pompa, descendió en la Plaza de San Marcos, y a la entrada del Palacio lo esperó Alejandro. Cuéntase que cuando Barbarroja se arrodilló ante el Dapa, éste le puso el pie en el cuello y pronunció estas palabras de un profeta: Pisaré el áspid y el basilisco y hallaré el león y el dragóns; a lo cual Barbarroja, soberbio en su humillación, replicó: -Me humillo delante de Pedro. no de vos.. Una losa de mármol rojo en el atrio de San Marcos señala el sitio de la humillación del Emperador de Oriente.

Sea o no cierto el detalle, lo esencial es que Venecia con su triunfo, reslableció al Papa: que en Venecia recibió éste la adhesión y sometimiento de todos los que lo habían combatido o permanecian indecisos y que el Papa reconoció a su vez el servicio de la República con tres monumentos históricos. el primero de los cuales consistió en concesiones honorificas al Dux: el de llevar delante de si un cirio encendido, una espada, un quitasol, un sillón, un cojin de lejido de oro, trompelas y estandartes; y le regaló un anillo de oro diciéndole:

- Recibidlo de mi mano como una señal del imperio sobre el mar: vos y vuestros sucesores casaos con él lodos los años. a fin de que la posteridad sepa que el mar os pertenece por derecho de conquista y debe estar sometido a vuestra república como lo está la esposa al esposo. (Daru, Histoire de Venise. tomo I, pág. 48, ed. 1838).

El cronista que cita el Sr. Errázuriz Urmeneta (pág. 214. La 


\section{Los fiestos nupciales en Venecia}

ciudad de los Dux) dice en su lengua, transparente para nosotros:

...et habluda vittoria Venezia, et zante a casa, missier lo Papa andó con le brazzia averte contra di missier lo Doxe, en rezavando la sua grandezza, digando: ben venga lo signior de tutto lo mar salso: imper quello chello la ben conquéstato; et qua missier lo Papa si le presenta un anello d'oro digando que lo sposare lo mar sicome l'homo sposa la donna per esser lo signior. E questo nu concedemo perpetualmente da fare agni annos. (Venecia, edición 1584).

Cuatrocientos años más tarde el Papa Pio IV hizo colocar en la sala real del Vaticano una inscripción que recordaba la victoria veneciana y el restablecimiento del Papa Alejandro III mediante ella. En 1635 el Papa Urbano VIII hizo quitar la inscripción y la República protestó, se negó a recibir al Nuncio del Papa y su sucesor, Inocencio $X$. hubo de reponerla.

$Y$ finalmente, hay una declaración oficial ante notario hecha por la Santa Sede y cuyo texto está en la Historia de Venecia del Dux Daudolo. Por esa declaración la Santa Sede reconoce los servicios de Venecia en el restablecimiento en la silla de Pedro de Alejandro III y la victoria de aquéllos contra el Emperador de Oriente.

Bastan estos testimonios para que quede en claro que el reconocimiento por el Papado y la confirmación, hecha en la forma de la época (no muy distinta de las actuales formas). del imperio del mar Adriático ejercido por Venecia fueron efectivos; no sin que los modernos. llevados del espiritu soberbio que con el nombre de erenovación de valores, pretende rehacer la historia a su sabor, ha puesto en duda el origen coficials de la ceremonia nupcial de Venecia y el mar.

$\mathrm{Y}$ digo coficial, porque se ignora-y en esto cabe una legítima duda-si ya existia un principio de ceremonia. fácil de concebir dados los antecedentes expuestos. y si el Papa no hizo sino confirmarla y darle cuerpo. Es lo cierto que en tanto duró la buena amistad entre la República veneciana y el $\mathrm{Pa}$ - 
pado, el Pontífice cada año envió al Dux un anillo de oro para su casamiento con el mar.

La ceremonia revistió la pompa que ha hecho cêlebres las fiestas venecianas. El día de la ascensión del Señor. el Dux abordaba la galera regia Bucentauro, de tres bancas de remeros, toda dorada y tallada, y cubierta de sedas y terciopelos brillantes; y bajo la carpa o tienda de la cubierta, sostenida por columnas y estafermos tallados, tomaba colocación el mundo oficial de Embajadores, nobles del Consejo e invitados - visitantes extranjeros, todos ricamente ataviados, y partian de la Plaza de San Marcos hacia San Pedro del Castillo, cede de la catedral, y alli embarcaban al coro de canónigos y al obispo. Bendecia éste un vaso de agua del mar y la arrojaba al océano: y desde allí, siguiendo el cortejo de centenares de embarcaciones y góndolas empavesadas, entre el estruendo de salvas de artillería y vocerio de la gente, enderezaban rumbo al Lido; y en saliendo a la mar libre. el Dux se iba a la proa y en un momento señalado, callando músicos, disparos y voces. recibia el anillo nupcial de manos del obispo y lo arrojaba al mar. diciendo en altas voces: cDesposamus te mare in signum vere perpetuique dominis: palabras a las cuales seguía la confirmación popular de disparos y aclamaciones.

Y tornando a San Marcos oian Dux y comitiva una misa solemne; y en la tarde, reunía el Dux a su mesa a los Embajadores y nobles venecianos en fastuoso banquete.

A esa época de la fiesta transcripta, hacia el 1500 , se refiere un cuadro trazado por Ruskin en cLos Pintores Modernos, al hablar de Giorgione, el gran pintor de la escuela veneciana.

Nada daría mejor idea de la suntuosidad y hermosura de la fiesta que la decoración soberbia que la encuadraba. He aquí a Ruskin;

-Mirado de vida poderosa, desde la montaña roquiza hasta 
el mar, muy joven aún (Giorgione) iba a la ciudad de mármol y era uno de los corazones más ardientes.

- ¿Una ciudad de mármol he dicho? No: más bien una ciudad de oro, empedrada de esmeraldas, donde cada piñón, cada torrecilla brillaba bajo su revestimiento de oro o de jaspe. A su lado el mar gemia en largos suspiros de sus olas cambiantes. Terribles, profundos y majestuosos como el mar. los hombres de Venecia partian en apostura de poder y de guerra; puras como pilares de alabastro eran sus mujeres y sus doncellas: sus caballeros, nobles de la cabeza a los pies, hacian brillar los reflejos bronceados de su armadura enmohecida por el mar y ocultar sus debilidades bajo los pliegues de su manto. de un rojo sangriento. Desconociendo el miedo. fieles, pacientes. impenetrables, implacables_cada una de sus palabras fijaba un destino-tomaban puesto en el Senado... Nunca Venecia fué más grande que cuando sus capitanes la descubrian por la tarde, desde lo alto de sus mástiles. y una línea de sol poniente parecia desvanecerla....

Asi Venecia, fastuosa y rutilante, derrochaba en fiestas con tanta liberalidad como el sol derrocha el oro de su lumbre y los colores de su iris: hasta que surgió d'uom fatales del canto de Manzoni y en campo Fornio, después de volar con sus águilas de campanario en campanario a través de Italia, señaló con su espada los nuevos límites de la Europa y adjudicó Venecia al Austria en 1789. Así acabó la República y cesaron sus cantos nupciales... de los cuales como un eco ancestral de tiempos viejos, son los que entona el gondolero conduciendo por los canales hacia el Lido las parejas balbucientes que hoy sueñan sobre las aguas quietas que el sol ensangrienta.

Asi, durante mil cuatrocientos años las aguas de la Laguna Veneciana fueron batidas por los remeros de las fiestas nupciales. 
De 400 a 943 por la fiesta de los novios, de la nobleza que se casaban juntos un día del año;

De 944 a 1379 por la .Fiesta de los casados», eminentemente popular. costeada por los nobles y el tesoro ducal;

De 1177 a 1789 la fiesta nupcial del Dux con el Adriático. fiesta nacional, legalizada por el Papado.

En todas ellas tomó parte el pueblo. la nobleza y el gobierno de la República.

No obstante, D. Augusto Iglesias, en una novela, puso en boca de uno de los personajes la afirmación de que los venecianos ignoraban el significado del casamiento del Dux con el Adriático.

En un articulo de critica hice notar al Sr. Iglesias su error: pero él lo sostuvo valientemente en un articulo publicado en -Sucesos, al cual repliqué con algunas citas.

Contestación a ese articulo es su estudio publicado en esta revista en su número de Diciembre.

Ya no niega que los venecianos sabian el significado de esas bodas simbólicas, como no podrá negar que los chilenos sabemos que celebramos el dieciocho de Septiembre de cada año; pero quiere ahora negarle su carácter propio de fiesta y de nupcias para convertirlo en un sacrificio deprecatorio, imitado de los griegos, los hebreos y pueblos bárbaros de la Oceania. Pudo citar cien ejemplos de objetos arrojados al mar; ninguno con el carácter y fin del anillo tirado al océano por el Dux de Venecia.

Si una costumbre cumplida durante toda la vida independiente de un país por más de mil años no es propio de tal país ¿qué puede serlo?

El ejemplo que cita el Sr. Iglesias no tiene carácter nupcial, sino de sacrificio deprecatorio. Es el de aquel tirano de Sausos. Policrates, cuya fortuna asombraba a su amigo Amasis, rey de Egipto. Temeroso de los Euménides, le aconseja inflingirse un dolor, desprenderse de algo amado, para que los dioses celosos le perdonen su inalterable fortuna. Y Policrates se desprende y arroja al mar un anillo de esmeralda, tallado por un samiense, que no salía de su dedo. 
¡Fué pequeño sacrificiol

Las Euménides lo rechazaron. Un pescado cogido al siguiente día llevaba el anillo en el vientre y fué devuelto a Policrates. Amasis, temeroso de las celestes vengadoras, rompió con un amigo cuya fortuna era excesiva y Policrates murió poco después asesinado.

Quien conoza algo de los griegos sabe que entre las divinidades a que su creadora fantasía dió cuerpo y vida están las Erinnias. llamadas también las Furias.

Policía suprema del cielo, guardianas de la vida, la religión y la fe jurada, eran también supremas compensadoras que no toleraban ni una excesiva fortuna, ni un dolor excesivo; y atenuaban la primera con reveses y mitigaban el segundo con venganzas. La sangre derramada les infundia sed de sacrificio, una embriaguez delirante de odio y persecución: e implacables y tenaces no paraban hasta compensar con sangre la sangre vertida.

La pacificación de las almas con el progreso de la sociabilidad. el gobierno y la filosolia moral dulcificaron a las Erinnias, y el genio humanitario de Sölocles las transformó en Euménides, divinas compensadoras de los excesos humanos, personificación divina de la vindicta pública, que no dejaban impunes los crímenes de los poderosos ni aún de los dioses.

En el fondo de ese mito. que es el alma de esa tragedia griega, ¿qué hay sino el pensamiento fundamental de todas las religiones. de que la vida del hombre es una mezcla de pesares y alegrias: que de las entrañas de la felicidad nace el germen del dolor. y del acibar de la pena, fluye el bálsamo suavizante y a las veces una felicidad depurada y profunda: de que, en fin. trafagamos en un valle de lágrimas y nada dura. sino Dios, su justicia y su misericordia y que la universal palingenesia de los filósofos está fuera de este mundo?

Las Erinnias, feas. deformes y trágicas primero. las Euménides severas bajo el velo que las cubría eran para los griegos las ejecutoras del Destino y también sus suavizadoras. Celosos los Dioses de la felicidad y grandeza humanas, no toleraban que un hombre pudiera asemejarse a ellos. Pindaro interrumpe 
sus loas elocuentes temeroso de atraer sobre sus héroes la venganza de las Euménides y las invoca; o recuerda al triunfador laureado que debe aplacarlas con dones o sacrificios.

A la luz de estas creencias, el Consejo de Amasís o Policrates se explica bien; y sea el caso cierto, sea cuento. es una ilustración o un apólogo que las apoya.

¿Qué hay de común entre el sacrificio del anillo de Policrates y el anillo vulgar de oro que simbolizaba las nupcias del Dux con el mar? ¿Qué puede haber de semejante entre un sacrificio expiatorio o deprecatorio y una boda simbólica? Si polícrates en vez de un hermoso anillo hubiera amado entrañablemente su caballo de guerra, el sacrificio habria sido distinto.

En cambio. las costumbres venecianas de catorce siglos y lucha heróica contra los piratas, el Imperio de Oriente, el Papado y las repúblicas, aristocracias y monarquias de ambas orillas del Adriático para dominar en el mar sin contrapeso. cerrarlo al comercio extranjero y al tránsito de guerra. explica bien el símbolo de las bodas con el mar, que debía estarle sometido como la esposa al marido, según la fórmula papal.

El Sr. Iglesias ha puesto en duda la veracidad de las cifras que antes habia hecho.

Tengo sobre mi mesa, dice, (Atenea, pág. 62) los volúmenes de la Histoire de la Republique de Venise ey, como en el caso de Ruskin. la he revisado cuidadosamente sin encontrar nada de lo que afirma $\mathrm{mi}$ bondadoso amigo. Aunque sin duda alguna no debo achacarle culpas, porque la persona a quien acude el Sr. Correa publicó su obra en 1838 y Daru murió en 1829. ¡Mal podía el conde famoso escribir una obra después de muerto!,

De Daru se trata. Para saber lo que dice no he consultado bibliografias; he leido la historia. Si la obra se publicó antes o después de morir lo ignoro. La que tengo fué impresa en 
Bruselas, en 1838, por Adolfo Walhen y C. ${ }^{a}$ : consta de dos volúmenes gruesos y grandes, a dos columnas por página y no lleva indicación de ser primera o siguiente edición. IOh! me olvidaba: no se llama Histoire de la Republique de Venise. sino simplemente Histoire de Venise.

En la pág. 48 del tomo I están las palabras con que Alejandro III entregó al Dux Sebastián Ziani el anillo de bodas y las concesiones honorificas que le hizo: y antes y después de esa página, la relación de la batalla ganada a Oton y las consecuencias. Seria útil al Sr. Iglesias leer además el libro V. págs. 88 y siguientes en que se detallan las medidas tomadas y las luchas emprendidas por el gobierno veneciano para mantener su absoluta soberanía sobre el Adriático.

Más cuidado deberá tener si lee a Ruskin, pues como trata de pintura, escultura y arquitectura, sólo de paso alude a incidencias politicas: pero en la pág. 21 del tomo I habla de las luchas de Venecia con el Papado. de la entrevista de Barbarroja con Alejandro III. de las nupcias del Dux con el Adriático. etc.; y en el Indice Veneciano, que debe servir de guia al amante de las artes, enumera algunos cuadros y motivos arquilectónicos que se refieren a la soberania de Venecia sobre el mar. En Errázuriz U. hallará trascripciones de cuadros y relato de las nupcias en 1499.

No ha revisado cuidadosamente sus libros, el Sr. Iglesias. Ha argumentado como un tinterillo que conoce las leyes de oidas. No está bien en quien se titula profesor de historia. El menos versado en ellas no confundiría las bodas del Dux con el sacrificio hecho por Policrates a las Euménides ni mucho menos con la tirada de Jonás al mar para que se lo tragara una ballena... de tan anchas tragaderas como cualquier exégeta anticristiano.

Santiago 12 de Febrero de 1926. 